\title{
Design of Propeller Series Optimizing Fuel Consumption and Propeller Efficiency
}

\author{
Mina Tadros ${ }^{1,2, *(\mathbb{C}, \text { Manuel Ventura }}{ }^{1}$ and Carlos Guedes Soares ${ }^{1}(\mathbb{C})$ \\ 1 Centre for Marine Technology and Ocean Engineering (CENTEC), Instituto Superior Técnico, Universidade \\ de Lisboa, Av. Rovisco Pais 1, 1049-001 Lisboa, Portugal; manuel.ventura@centec.tecnico.ulisboa.pt (M.V.); \\ c.guedes.soares@centec.tecnico.ulisboa.pt (C.G.S.) \\ 2 Department of Naval Architecture and Marine Engineering, Faculty of Engineering, Alexandria University, \\ Alexandria 21544, Egypt \\ * Correspondence: mina.tadros@centec.tecnico.ulisboa.pt
}

Citation: Tadros, M.; Ventura, M.; Guedes Soares, C. Design of Propeller Series Optimizing Fuel Consumption and Propeller Efficiency. J. Mar. Sci. Eng. 2021, 9, 1226. https:// doi.org/10.3390/jmse9111226

Academic Editor: Dracos Vassalos

Received: 26 September 2021 Accepted: 3 November 2021 Published: 5 November 2021

Publisher's Note: MDPI stays neutral with regard to jurisdictional claims in published maps and institutional affiliations.

Copyright: (c) 2021 by the authors. Licensee MDPI, Basel, Switzerland. This article is an open access article distributed under the terms and conditions of the Creative Commons Attribution (CC BY) license (https:/ / creativecommons.org/licenses/by/ $4.0 /)$.

\begin{abstract}
This paper presents a comparison between different types of propellers operated in calm water to evaluate their performance behind hulls and in open-water conditions. A bulk carrier is chosen as a case study to perform the simulation and to evaluate the performance of several propeller series, namely the Wagengein B-series, Kaplan 19A, and MAU. Firstly, optimization procedures are performed by coupling a propeller design tool and a nonlinear optimizer to find the optimum design parameters of a fixed-pitch propeller. This optimization model aims to design the propeller behind the hull at the engine operating point with minimum fuel consumption and maximum propeller efficiency. The two main objectives of this study and the constraints are defined in a single fitness function to find the optimum values of the propeller geometry and the gearbox ratio. By considering the benefits of the single-objective over the multi-objective optimization problem, this model helps to find the optimum propeller for both defined objectives instead of only considering one of them, as in previous studies. Then, based on the optimized parameters, the propeller performance is calculated in open-water conditions. From the computed results, one can observe the importance of considering the hull-propulsor interaction in propeller selection.
\end{abstract}

Keywords: bulk carrier; single objective optimization model; minimum fuel consumption; maximum efficiency; Matlab and NavCad

\section{Introduction}

The marine propeller is an essential part of the conventional ship propulsion system that is composed of the main engine, transmission shaft, and propeller. It is used to propel the ship based on the power generated and transmitted from the main engine [1]. Propeller selection is an important process as it depends on the stern hull form, directly affecting the ship speed and ensuring the sustainability of the propeller performance during the ship life. The chosen propeller affects the engine operating point reflecting the engine speed and power as well as the fuel consumption [2], which in turn affect the energy efficiency index of the ship for reducing the level of exhausted carbon dioxide $\left(\mathrm{CO}_{2}\right)$; namely, either the energy efficiency design index (EEDI) in new ships or the energy efficiency of the existing ship index (EEXI) for current ships as defined in [3].

Throughout the years, research has been performed to design new propellers according to the market needs and improve the blade shape of the existing propellers [4,5]. The main interests of research are in improving the stern wakes [6], increasing propeller efficiency [7], and reducing problems of cavitation [8] to reduce the fuel consumed [9], as well as ensuring the sustainability of the propeller [10].

Two types of techniques are considered; the first one tailored a customized combination of the propeller parts in the three-dimensional mode to comply with the performance 
of several specific ships as well as improving the existing typical propeller used. Propeller series, the second choice, are widely used as their characteristics are represented by polynomial equations, and can easily be coupled and integrated into other codes [11]. Wageningen B-series are most commonly used due to the availability of the polynomial equations [12,13], in comparison to the systematic information of the other propeller series that require efforts to predict propeller performance through interpolation procedures among the propeller geometry as well as the number of propeller blades [14].

To achieve the optimum propeller design, operation research, an analytical method to solve complex problems and assist in decision making, is integrated with several propeller software applications to find the optimal solution according to the study's objective [15]. Both single- and multi-objective optimization techniques are used to fulfil the objective of the studies.

In terms of propeller efficiency, different tools have been developed to maximize the propeller efficiency of several case studies. Radojčić [16] used a sequential unconstrained optimization technique (SUMT) to select the optimum propeller geometry from Wageningen B-series at the maximum propeller efficiency. Suen and Kouh [17] used a genetic algorithm (GA) to find an optimum propeller when the efficiency is maximized. Benini [18] used GA to maximize the propeller efficiency and thrust coefficient by considering the cavitation constraints. Lee et al. [19] performed a modification to the expanded area ratio (EAR), which led to an increase in propeller efficiency by $2 \%$. Gaafary et al. [20] selected a marine propeller at maximum efficiency while considering the limitation of both material strength and cavitation issues. Vesting and Bensow [21] used the non-dominated sorting algorithm II (NSGA-II) to find the propeller geometry at maximum propeller efficiency while minimizing the pressure pulse and cavitation issues. Xie [22] used the same optimization technique to maximize the thrust coefficient in addition to the propeller efficiency. Mirjalili et al. [23] used a multi-objective technique to maximize the propeller efficiency and minimize cavitation issues. Tadros et al. [7] coupled a marine propeller code implemented in OpenProp [24] with Matlab to maximize the propeller efficiency by finding a set of optimum propeller geometries.

In terms of structure, Khan [25] used a Fortran subroutine to calculate the propeller characteristics and the force distribution to study the deformation on the blades. Karim and Ikehata [26] extended the paper written by [17] by considering the material strength based on the correction made to the Reynolds number. Pluciński et al. [27] optimized the material fiber orientations of a self-twisting composite marine propeller to maximize twist using a developed model coupling boundary the element (BEM) and the finite element (FEM) method, and Gaafary et al. [20] and Tadros et al. [28] found the optimal propeller geometry while complying with the limitation of material strength according to international regulations [29].

In terms of vibration, Chen and Shih [30] used GA to minimize the vibratory excitations in addition to maximizing the propeller efficiency. Both objectives are combined into one fitness function, and the optimization model successfully shows its ability to obtain an optimal set of propeller parameters. Lee et al. [19] used optimization procedures to find propeller geometry, achieving lower cavitation problems and thus vibrations with an MAU propeller. Tadros et al. [31] considered the tip speed as a constraint while searching for the optimum propeller at the minimum fuel consumption.

In terms of operation, Michalsk [32] developed an algorithmic method to select the different parameters of a ship propulsion system, taking into account the changes in waterway dimensions, ship resistance, and service speed. Gaggero et al. [8] increased the ship speed by improving the propulsive efficiency using a BEM coupled with GA. Tadros et al. [31] selected an optimum propeller at different ship speeds to minimize the fuel consumption as a decision-making tool.

In terms of fuel consumption, Nelson et al. [33] used sequential quadratic programming (SQP) to optimize ship hull and propeller, thus reducing fuel consumption along the ship's lifetime. Tadros et al. [28] selected the propeller at the engine operating point 
with the minimum brake specific fuel consumption (BSFC). Then, a comparison study was performed using the developed optimization code in [34] when the propeller was selected at the maximum propeller efficiency, minimum BSFC, and minimum fuel consumption. The last case shows a significant reduction in fuel consumption in liters per nautical mile by $4.5 \%$ when compared to the first two cases. Tadros et al. [31] extended the previous work to find the optimum propeller while minimizing the fuel consumed for different ship speeds. The results assist ship designers in selecting the optimum propeller during the design stage of the ship, as well as aiding the shipmaster in operating the ship at a certain speed with a reduction in the fuel consumed.

In this study, the numerical model developed by [31] is adapted to extend the previous works mentioned in the literature review, by optimizing the propeller geometry as well as the operational point at both the maximum propeller efficiency and minimum engine fuel consumption for a given ship speed, in order to ensure maximum propeller performance. It follows the same concept of design presented by Chen and Shih [30] that used several objectives combined into one single equation. The two objectives are combined into one fitness function in addition to the defined constraints; therefore, the optimization problem is solved as a single-objective function defined into the fitness function. This optimization problem is applied to various propeller series, namely the Wagengein B-series [13], Kaplan 19A [35], and MAU [36], to compare the performance of the selected propellers installed in a bulk carrier, highlight the variation of propeller parameters, and show the effect of the hull-propulsor interaction. This will help the ship and propeller designers to obtain a wide overview of the propeller performance and make decisions for selecting the optimum one.

The rest of the paper is organized as follows: Section 2 gives a presentation of the specification of the bulk carrier ship and the installed engine; Section 3 presents a description of the developed numerical model; and Section 4 presents the types of propellers considered in this study as well as the equations used to compute the propeller performance. Section 5 presents a brief description of the optimization model, including the objectives and constraints defined in the fitness function; the results are discussed in Section 6, and conclusions are presented in Section 7.

\section{Main Specifications of Bulk Carrier}

In this paper, a bulk carrier ship is selected to perform the simulation. This ship size is selected due to its importance in transporting bulk cargo worldwide [37]. The selected ship is powered by one MAN four-stroke marine diesel engine [38] fueled by marine diesel oil with $7140 \mathrm{~kW}$ driving one fixed-pitch propeller (FPP). Tables 1 and 2 show the main characteristics of the selected ship and the installed engine, while Figure 1 shows the total resistance of the ship at various ship speeds in calm water.

Table 1. Main characteristics of bulk carrier.

\begin{tabular}{ccc}
\hline Item & Unit & Value \\
\hline Length waterline & $\mathrm{m}$ & 154 \\
Breadth & $\mathrm{m}$ & 23.11 \\
Draft & $\mathrm{m}$ & 10 \\
Displacement & tonne & 27,690 \\
Service speed & knot & 14.5 \\
Maximum speed & knot & 16 \\
Number of propellers & - & 1 \\
Type of propellers & - & $\mathrm{FPP}$ \\
Rated power & $\mathrm{kW}$ & 7140 \\
\hline
\end{tabular}


Table 2. Main characteristics of MAN 14V 32/44 CR.

\begin{tabular}{ccc}
\hline Item & Unit & Value \\
\hline Engine builder & - & MAN Energy Solutions \\
Brand name & - & MAN \\
Bore & $\mathrm{mm}$ & 320 \\
Stroke & $\mathrm{mm}$ & 440 \\
Displacement & liter & 4954 \\
Number of cylinders & - & 14 \\
Rated speed & $\mathrm{rpm}$ & 750 \\
Rated power & $\mathrm{kW}$ & 7140 \\
\hline
\end{tabular}

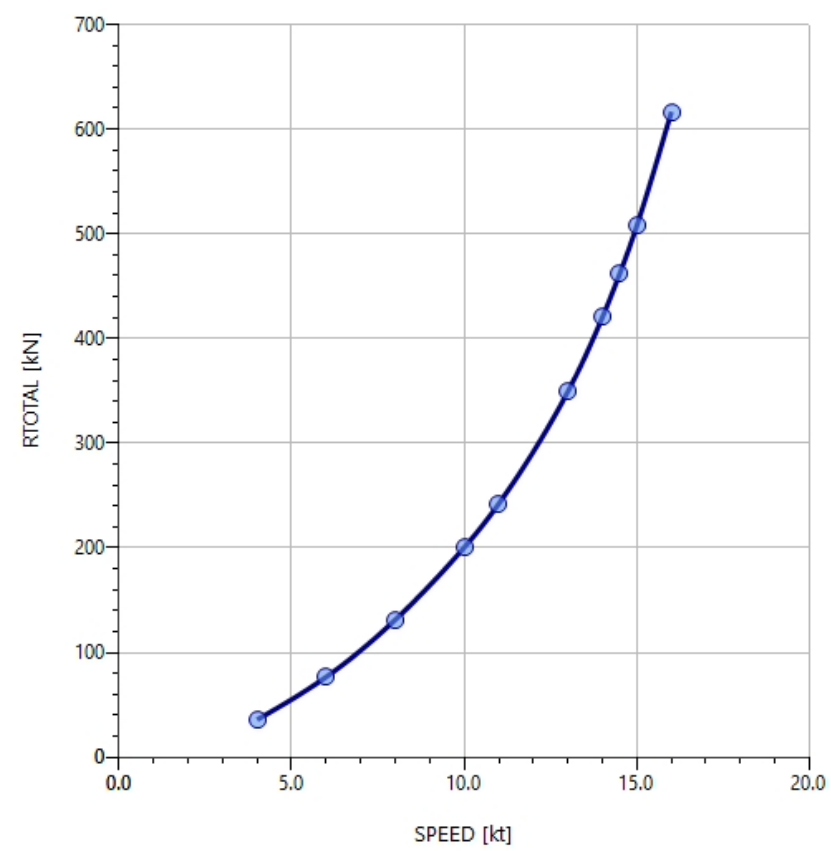

Figure 1. Total resistance of the bulk carrier at different ship speeds.

\section{Numerical Model}

The propeller optimization model previously developed by Tadros et al. [31] is used in this study to select the optimum propeller design for several propeller series, namely the Wagengein B-series, Kaplan 19A, and MAU. In this model, NavCad software, as a premium edition, can be coupled to a third party; therefore, it is adapted to be coupled to a local optimizer implemented in Matlab to perform the optimization procedures. The local optimizer used to evaluate the performance of the optimization method is fmincon, in order to find the minimum of a nonlinear multivariable function. It is based on an interior-point algorithm and requires the definition of an initial starting point for each variable, which is kept constant for the different simulated cases. It finds the optimal solution of $x$ to minimize the objective function, $f(x)$, and to verify the inequality, $c(x)$ and equality constraints, $c_{e q}(x)$, as in the following equations. More descriptions about the selected method are detailed in [39].

$$
\begin{array}{rc}
\text { minimize } & f(x) \\
\text { subjected to : } \quad c(x) \leq 0 \\
\\
c e q(x)=0 \\
l b \leq x \leq u b
\end{array}
$$

where $l b$ is the lower bounds and $u b$ is the upper bounds. 
As defined in the previous study, the model selects the propeller geometry, the operational point, and the gearbox ratio. The objective function of the optimization model is adapted in this paper to select the propeller at both the maximum propeller efficiency and the minimum fuel consumption.

To proceed with the computation using NavCad, the data of the ship must be defined in the software, including the main dimensions of the ship hull, the different ship speeds, and certain margin designs. The maximum allowable propeller diameter, as well as the propeller series, propeller types, and the method of propeller sizing, are also defined.

The ship resistance is computed using the methods presented by Holtrop and Mennen [40] and Holtrop [41] by taking into account the hull form factor as well as the correlation allowance according to the recommendation of ITTC [42]. Using the free-running solution, the propeller thrust is matched to the ship resistance computed at a given speed, $\mathrm{V}_{\mathrm{S}}$, and the number of propeller blades, $\mathrm{Z}$, by taking into account the hull-propulsor interaction, presented by the wake fraction, $\mathrm{w}$, the thrust deduction fraction, $\mathrm{t}$, and the relative-rotative efficiency, $\eta_{R R}$, as suggested by Holtrop and Mennen [40]. For the suggested FPP, NavCad can identify the suitable speed, N, that produces the appropriate thrust based on the input diameter, $\mathrm{D}$, pitch diameter ratio, $\mathrm{P} / \mathrm{D}$, expanded area ratio, EAR, and the gearbox ratio, GBR, while considering the cavitation, noise, and strength issues.

NavCad can compute the propeller performance and maximize the propeller efficiency; however, the engine load diagram is needed to minimize the fuel consumption. The engine load diagram presents a relation between the engine speed, engine brake power, BSFC, and several exhaust emissions. Therefore, the engine performance is computed based on the developed engine optimization model presented in $[43,44]$. The engine performance is then converted in a nondimensional way as presented in [45,46], which can be applied to any of the diesel engines with the same series. The MAN 18V32/44CR [38] is the engine simulated, and the performance is rescaled to fit other engines with different brake power. To ensure a better working engine performance based on the combustion process, the searching process in the engine load diagram is limited between $50 \%$ and $90 \%$ of the rated engine power. Otherwise, the engine cannot operate out of this area range for more than two hours.

\section{Propeller Performance}

The performance of the selected propellers is computed based on the regression model developed from the open-water analysis of each series. Figures $2-4$ show the general plan of each series to clarify the outline of propeller blades as well as the availability of the propeller duct. Furthermore, the range of the main propeller parameters are defined in Table 3; this includes the number of blades, the blade area ratio, the pitch diameter ratio, and the advance coefficient.

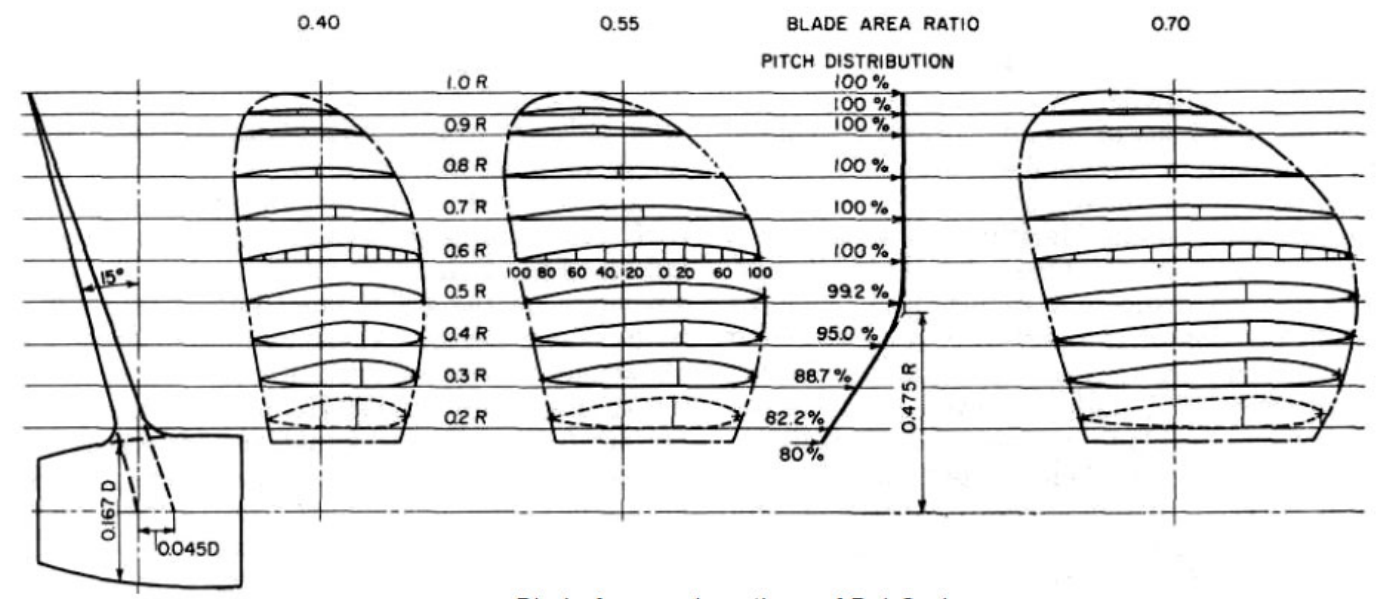

Blade form and sections of B. 4 Series

Figure 2. General plan of Wageningen B-series [14]. 

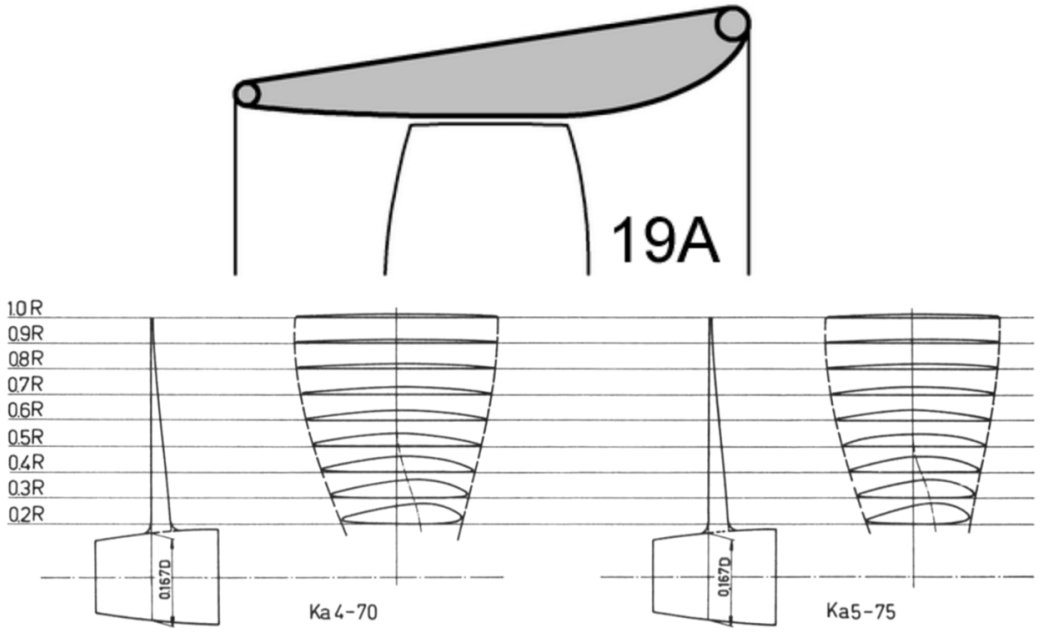

Figure 3. General plan of Kaplan 19A series [14].

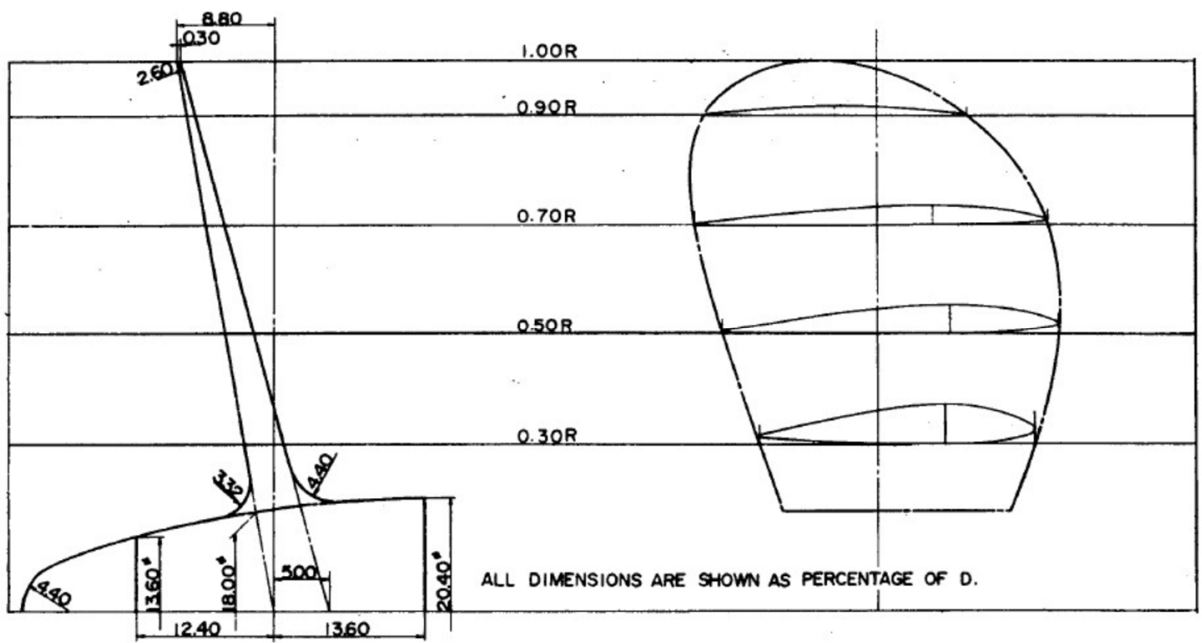

Figure 4. General plan of MAU series [14].

Table 3. Parameters of propeller series.

\begin{tabular}{cccc}
\hline Parameter & Wagengein B-Series & Kaplan 19A & MAU \\
\hline Number of blades & $3-7$ & $3-5$ & $3-6$ \\
\hline & $0.35-0.80$ for 3 blades & & $0.35-0.50$ for 3 blades \\
& $0.40-1.00$ for 4 blades & 0.65 for 3 blades & $0.40-0.70$ for 4 blades \\
Blade area ratio & $0.45-1.05$ for 5 blades & $0.55-0.7$ for 4 blades & $0.50-0.80$ for 5 blades \\
& $0.50-0.95$ for 6 blades & $0.65-0.95$ for 5 blades & $0.70-0.85$ for 6 blades \\
& $0.55-0.85$ for 7 blades & & $0.5-1.2$ \\
\hline Pitch/Diameter ratio & $0.5-1.4$ & $0.5-1.4$ & $0.05-1.5$ \\
\hline Advance coefficient & $0.05-1.5$ & $0.05-1.5$ &
\end{tabular}

The Wageningen B-series is considered the most common series used in several research studies due to the available regression model presented by polynomial equations and generated from test data of 120 propeller models [11,47]. The curves are developed based on an open-water analysis [13] and aim to be used in the preliminary stages of ship design.

The Kaplan 19A series is a ducted propeller series presented in [13]. This series is developed from the open-water analysis of the Kaplan series of non-cavitating propellers in a 19A accelerating nozzle. Although the results from tests are performed for only three 
and five blades, NavCad performs interpolation to fill this gap to be further used according to the needs. This type of propeller can be used to improve propulsive efficiency, providing more thrust and faster flow to the propeller [48].

The MAU propeller is a type of propeller series developed in Japan [36]. This series was known as the AU type, and then the section of blades was improved to reduce the cavitation problems and has since been known as the MAU type. Several companies use this series to fit the requirements of the propulsion systems of container ships, cargo ships, and tankers [49].

To predict the propeller performance, the general equations presented in [1] are used to compute the main propeller parameters such as the advance coefficient, $J$, the thrust coefficient, $K_{T}$, the torque coefficient, $K_{Q}$, and the propeller efficiency, $\eta_{0}$, as in the following equations.

$$
\begin{gathered}
J=\frac{V_{A}}{n D} \\
K_{T}=\frac{T}{\rho n^{2} D^{4}} \\
K_{Q}=\frac{Q}{\rho n^{2} D^{5}} \\
\eta_{0}=\frac{K_{T}}{K_{Q}} \frac{J}{2 \pi} \\
V_{A}=V_{S}(1-w) \\
T=\frac{R_{T}}{1-t}
\end{gathered}
$$

where $V_{A}$ is the advance speed, $n$ is the propeller speed, $\rho$ is the density, $R_{T}$ is the total resistance, $T$ is the thrust, and $Q$ is the torque.

The constraint limitations of the cavitation and noise values are presented in detail in [31], as suggested by [14].

\section{Optimization Model}

The optimization procedures used in this study are evaluated by the fitness function presented in Equation (9), which must be minimized. In general, the fitness function is composed of two parts, the objectives and the problem's constraints. By combining both parts, the problem is converted to an unconstrained problem that the optimizer can easily evaluate by finding the minimum value of the fitness function. Furthermore, to easily integrate the constraints into the fitness function, the static penalty function is used in order to be presented in a nondimensional way, as presented by Tadros et al. [31].

In this study, two objectives are added to the fitness function, the fuel consumption and propeller efficiency; each one is multiplied by a weight assumed to be equal in this study, due to the equal importance of the two objectives. Then the constraints, including cavitation, strength, and noise issues, as well as the searching area, are shown in the engine load diagram.

$$
\text { Fitness Function }=w_{1} \times F C+w_{2} \times \eta_{0}+R \sum_{i=1}^{j} \max \left(g_{i}(x), 0\right)
$$

where $F C$ is the fuel consumption, $w_{1}$ and $w_{2}$ are the weights for each objective, $g(x)$ is the static penalty function, $x$ is the number of variables, $j$ is the number of constraints, and $R$ is a penalty function.

\section{Results}

Based on the developed propeller optimization model in the Matlab environment, the nonlinear optimizer is able to select the propeller geometry, the propeller operating 
point, and the gearbox ratio of a propulsion system of a bulk carrier driven by an FPP at a service speed (14.5 knots). First, the propeller parameters are optimized behind the ship hull, then based on the computed parameters, the propeller performance is simulated in open-water conditions for comparison. Different propeller series are considered in this study, and the fitness function can evaluate the optimization model by minimizing the fuel consumption, maximizing the propeller efficiency, and complying with the noise and cavitation limitations. In addition, the resonance problem of the propulsion system is avoided by ensuring the propeller at five blades never coincides or is a multiple of the number of engine cylinders (14 cylinders), as suggested by [31].

In Table 4, a comparison study is performed to evaluate the propeller performance of the different propeller series by taking into account the hull-propeller interaction. The three propellers reach the same thrust to struggle against the ship resistance at a given speed, while the propeller geometry and the operational point vary between the cases. Figure 5 presents the propeller curve among the engine load diagram, and it shows that the propeller curves of all three propeller series are almost aligned and show the same behavior.

Table 4. Comparison between the optimized results for different propeller series.

\begin{tabular}{|c|c|c|c|c|c|c|c|c|}
\hline & Parameters & Unit & $\begin{array}{c}\text { Behind } \\
\text { Hull }\end{array}$ & $\begin{array}{l}\text { Open } \\
\text { Water }\end{array}$ & $\begin{array}{c}\text { Behind } \\
\text { Hull }\end{array}$ & $\begin{array}{l}\text { Open } \\
\text { Water }\end{array}$ & $\begin{array}{c}\text { Behind } \\
\text { Hull }\end{array}$ & $\begin{array}{l}\text { Open } \\
\text { Water }\end{array}$ \\
\hline \multicolumn{3}{|l|}{ Propeller Type } & \multicolumn{2}{|c|}{ Wageningen B-Series } & \multicolumn{2}{|c|}{ Kaplan 19A } & \multicolumn{2}{|c|}{ MAU } \\
\hline \multirow{13}{*}{$\begin{array}{c}\text { Propeller } \\
\text { characteristics }\end{array}$} & $\mathrm{D}$ & {$[\mathrm{m}]$} & \multicolumn{2}{|c|}{6} & \multicolumn{2}{|c|}{5.11} & \multicolumn{2}{|c|}{6} \\
\hline & EAR & {$[-]$} & \multicolumn{2}{|c|}{0.71} & \multicolumn{2}{|c|}{0.75} & \multicolumn{2}{|c|}{0.8} \\
\hline & $\mathrm{P}$ & {$[\mathrm{m}]$} & \multicolumn{2}{|c|}{4.45} & \multicolumn{2}{|c|}{5.188} & \multicolumn{2}{|c|}{4.77} \\
\hline & $\mathrm{P} / \mathrm{D}$ & {$[-]$} & \multicolumn{2}{|c|}{0.74} & \multicolumn{2}{|c|}{1.01} & \multicolumn{2}{|c|}{0.79} \\
\hline & Speed & [RPM] & 98 & 119 & 107 & 129 & 90 & 109 \\
\hline & Thrust & {$[\mathrm{kN}]$} & 569.88 & 461.81 & 569.88 & 461.81 & 569.88 & 461.81 \\
\hline & Torque & {$[\mathrm{kN} \mathrm{m}]$} & 435.1 & 411.8 & 425.2 & 491.5 & 464.7 & 448.4 \\
\hline & $\eta_{0}$ & {$[\%]$} & 0.59 & 0.6713 & 0.55 & 0.5169 & 0.6 & 0.6718 \\
\hline & $J$ & {$[-]$} & 0.474 & 0.6267 & 0.51 & 0.6762 & 0.5153 & 0.683 \\
\hline & $K_{T}$ & {$[-]$} & 0.1608 & 0.0883 & 0.2565 & 0.1416 & 0.1901 & 0.1048 \\
\hline & $K_{Q}$ & {$[-]$} & 0.02047 & 0.0131 & 0.0374 & 0.02947 & 0.02584 & 0.01696 \\
\hline & $w$ & {$[-]$} & 0.377 & 0 & 0.377 & 0 & 0.377 & 0 \\
\hline & $t$ & {$[-]$} & 0.189 & 0 & 0.189 & 0 & 0.189 & 0 \\
\hline \multirow{4}{*}{ Cavitation } & \multirow{4}{*}{$\begin{array}{c}\text { Tip Speed } \\
\text { EAR min } \\
\text { Average loading } \\
\text { pressure } \\
\text { Back Cavitation }\end{array}$} & {$[\mathrm{m} / \mathrm{s}]$} & 30.77 & 37.39 & 28.6 & 34.66 & 28.3 & 34.31 \\
\hline & & {$[-]$} & 0.46 & 0.415 & 0.48 & 0.488 & 0.46 & 0.415 \\
\hline & & {$[\mathrm{kPa}]$} & 28.4 & 23.01 & 29.19 & 29.86 & 25.23 & 20.44 \\
\hline & & {$[\%]$} & 2 & 2 & 2 & 2 & 2 & 2 \\
\hline $\begin{array}{c}\text { Gearbox } \\
\text { characteristics }\end{array}$ & GBR & {$[-]$} & \multicolumn{2}{|c|}{6.93} & \multicolumn{2}{|c|}{6.49} & \multicolumn{2}{|c|}{7.50} \\
\hline \multirow{5}{*}{$\begin{array}{c}\text { Engine } \\
\text { characteristics }\end{array}$} & Speed & [RPM] & 679 & 825 & 693 & 840 & 676 & 819 \\
\hline & Brake Power & {$[\mathrm{kW}]$} & 4602.4 & 5344.2 & 4918.5 & 6940.2 & 4545 & 5339.9 \\
\hline & Loading ratio & [\%] & 64.5 & 74.8 & 68.9 & 97.2 & 63.7 & 74.8 \\
\hline & BSFC & {$[\mathrm{g} / \mathrm{kW} \mathrm{h}]$} & 187 & 0 & 192 & 0 & 186 & 0 \\
\hline & Fuel consumption & {$[\mathrm{L} / \mathrm{nm}]$} & 71.13 & 0 & 78.15 & 0 & 70.11 & 0 \\
\hline \multirow{3}{*}{$\begin{array}{l}\text { Exhaust } \\
\text { emissions }\end{array}$} & $\mathrm{CO}_{2}$ & {$[\mathrm{~g} / \mathrm{kW} \mathrm{h}]$} & 598.4 & 0 & 614.4 & 0 & 595.2 & 0 \\
\hline & $\mathrm{NO}_{\mathrm{x}}$ & {$[\mathrm{g} / \mathrm{kW} \mathrm{h}]$} & 7.11 & 0 & 7.61 & 0 & 6.91 & 0 \\
\hline & $\mathrm{SO}_{\mathrm{x}}$ & {$[\mathrm{g} / \mathrm{kW} \mathrm{h}]$} & 9.35 & 0 & 9.6 & 0 & 9.3 & 0 \\
\hline Simulation time & & [s] & 2239 & - & 1125 & - & 5628 & - \\
\hline
\end{tabular}

From the design point of view, Kaplan 19A shows the minimum propeller diameter compared to the other two series, where the diameters are identical and equal to the maximum allowable propeller diameter defined in the software. By varying the diameter of the propeller, the EAR and P/D also vary. EAR is maximized in the MAU type and vice versa in the case of the Wageningen B-series. P/D is maximized in the Kaplan 19A propeller while it is minimized in the case of the Wageningen B-series. Based on the large propeller diameter and lower propeller rotation, MAU and the Wageningen B-series have the highest propeller efficiencies. 


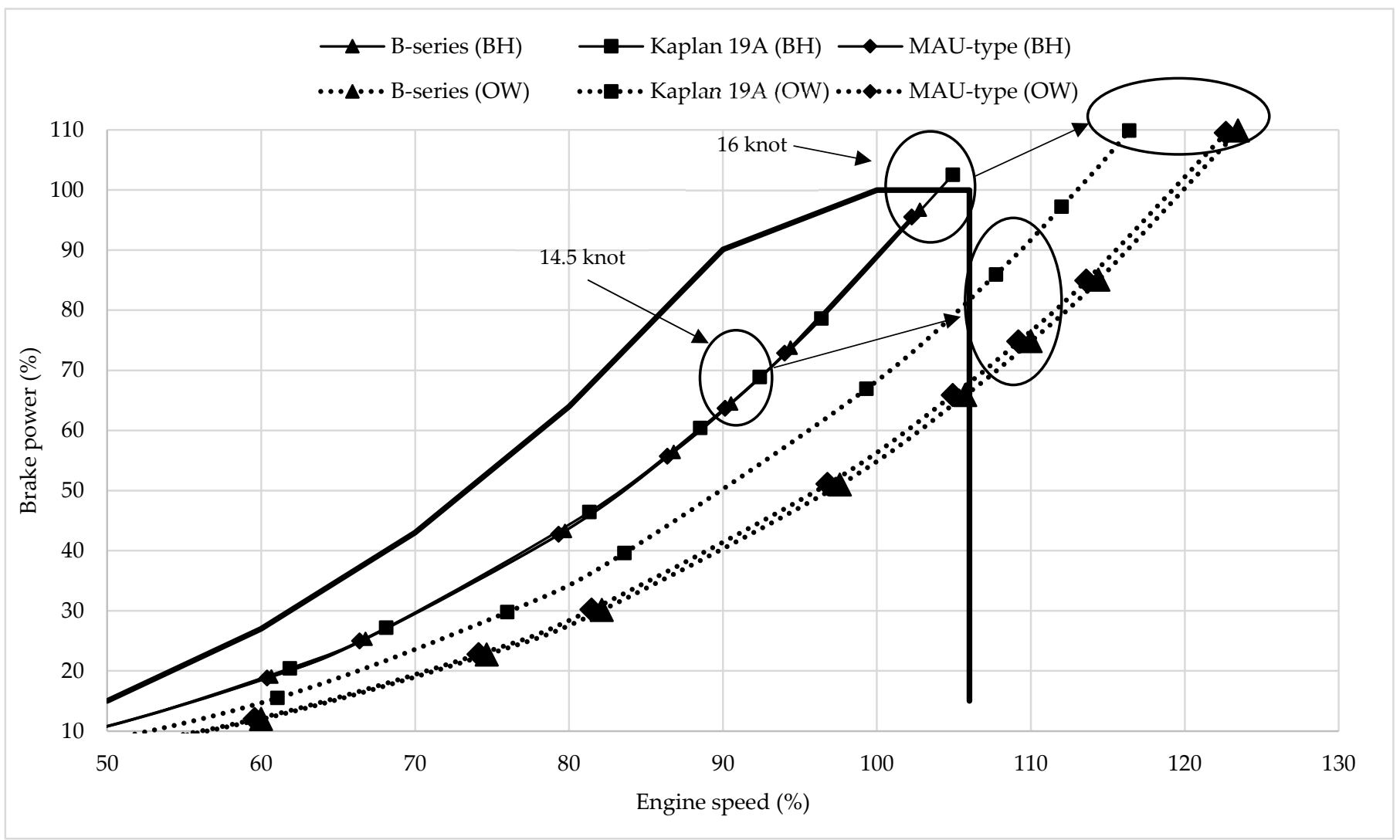

Figure 5. Propeller operating points in engine load diagram in both behind-hull and open-water conditions.

From the point of view of cavitation and noise, the three propellers comply with the limitations of the cavitation and the noise according to the suggested values presented in the manual of HydroComp [14]. It has been suggested that the average loading pressure must not exceed $65 \mathrm{kPa}$ according to Burrill and Emerson [50], the percentage of back cavitation must not exceed 15\% [51], and the tip speed must not exceed $46 \mathrm{~m} / \mathrm{s}$ for fiveblade propellers [14]. Additionally, the minimum EAR to avoid cavitation is always lower than the designed EAR for each case.

From the point of view of the operation, the MAU type has the lowest propeller speed, followed by the Wageningen B-series propeller and then the Kaplan 19A type. Therefore, the engine speed has the same order, while the values of the GBR are very close. The MAU-type propeller is designed and optimized at the lower engine brake power, followed by the Wageningen B-series and then the Kaplan 19A. As the values of BSFC are very close in this range of brake power, the MAU-type propeller shows a great reduction in fuel consumption with $1.5 \%$ and $10 \%$ more than the Wageningen B-series and Kaplan 19A, respectively.

From the simulation point of view, the optimization model found that the optimum propeller was the Kaplan 19A, which was up to five times faster than the other two cases.

After selecting the optimum propeller operating behind the hull in each series, the performance of each propeller is computed in open-water conditions for the same geometry by neglecting the effect of the wake fraction and the thrust deduction fraction. It has been shown in both Figure 5 and Table 4 that the operational points of the three propellers curves are changed, in particular at the design and maximum speeds.

From the propellers' characteristics, the advance coefficient increases due to the neglection of the Taylor wake fraction despite the increase in propeller speed. The propeller thrust is reduced and therefore the values of $\mathrm{K}_{\mathrm{T}}$ decrease. Furthermore, the values of $\mathrm{K}_{\mathrm{Q}}$ show a greater decrement than in the behind-hull condition. 
From the cavitation parameters, the tip speed increased due to the increase in propeller speed in open water, while the values of the other cavitation parameters are less than or equal to the ones in behind-hull conditions.

Due to the unchanged gearbox ratio and propeller simulation, the three propellers are operating out of the limits of the engine load diagram. An increment in brake power and engine speed has been noticed in the case of calm water compared to the propellers operating behind the hull. This leads to propeller operation failure, and the amount of emissions cannot be computed due to the absence of engine data in this area.

In general, this model helps marine designers determine and select the optimum propeller at the operating point with the minimum fuel consumption and maximum propeller efficiency instead of just considering any one of them, as well as considering the effect of the hull-propulsor interaction for realistic computations.

\section{Conclusions}

This paper presents a developed model coupling NavCad and Matlab to select an optimum propeller by maximizing the propeller efficiency and minimizing the fuel consumed for a given speed and number of blades, instead of only considering one of the two objectives. A comparative study is performed between three different propeller series, namely the Wagengein B-series, Kaplan 19A, and MAU. This tool is developed to help ship and propeller designers obtain a wide overview of propeller performance and make decisions to select the optimum one.

It has been concluded that:

1. The presented model can optimize the propeller performance in an adequate simulation time.

2. The configurations of the optimizer are kept the same for all simulated cases to present a clear comparison between the different cases.

3. The optimum propeller characteristics, propeller operation, and gearbox ratio are selected according to the input boundary limits as well as the defined constraints, where the propeller complies with the limitations of cavitation and noise.

4. The MAU type shows the most efficient propeller in terms of propeller efficiency and fuel consumption, followed by the Wagengein B-series and Kaplan 19A propellers.

5. When the propeller is selected at a lower brake power, a higher fuel reduction is achieved.

6. The hull-propulsor interaction significantly changes the propeller performance, and it must be considered for realistic design.

7. The model can be adapted to further simulate any type of propeller, while the objectives of the study can also be adapted according to specific needs.

Author Contributions: The concept of the problem was developed by M.T. The analysis was performed by M.T. and writing of the original draft manuscript was carried out by M.T., M.V., and C.G.S. All authors have read and agreed to the published version of the manuscript.

Funding: This work was performed within the scope of the Strategic Research Plan of the Centre for Marine Technology and Ocean Engineering (CENTEC), which is financed by the Portuguese Foundation for Science and Technology (Fundação para a Ciência e Tecnologia-FCT) under contract UIDB/UIDP/00134/2020.

Institutional Review Board Statement: Not applicable.

Informed Consent Statement: Not applicable.

Data Availability Statement: The data presented in this study are available on request from the corresponding author.

Conflicts of Interest: The authors declare no conflict of interest. 


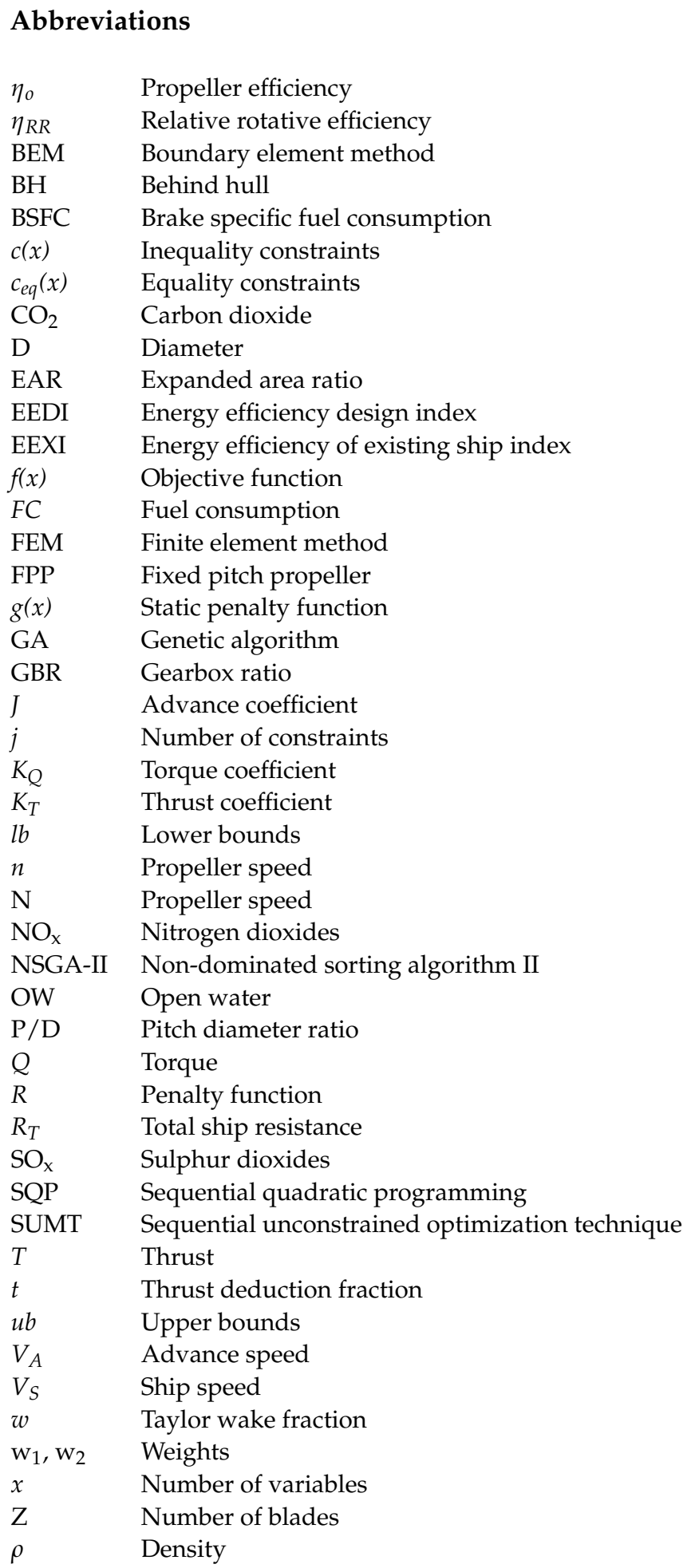

\section{References}

1. Carlton, J. Marine Propellers and Propulsion, 2nd ed.; Butterworth-Heinemann: Oxford, UK, 2012.

2. Moreira, L.; Vettor, R.; Guedes Soares, C. Neural Network Approach for Predicting Ship Speed and Fuel Consumption. J. Mar. Sci. Eng. 2021, 9, 119. [CrossRef]

3. DNV-GL. EEXI-Energy Efficiency Existing Ship Index. Available online: https://www.dnvgl.com/maritime/insights/topics/ eexi/calculation.html (accessed on 1 December 2020).

4. Wärtsilä. Propellers Efficiency and Manoeuvrability Improvements. Available online: https://www.wartsila.com/marine/build/ propulsors-and-gears / propellers (accessed on 1 July 2021). 
5. MAN Energy Solutions. Propulsion: MAN Alpha Propeller \& Aft Ship Solutions. Available online: https://www.man-es.com/ marine/products/propeller-aft-ship (accessed on 1 July 2021).

6. Taskar, B.; Yum, K.K.; Steen, S.; Pedersen, E. The effect of waves on engine-propeller dynamics and propulsion performance of ships. Ocean Eng. 2016, 122, 262-277. [CrossRef]

7. Tadros, M.; Ventura, M.; Guedes Soares, C. Optimization scheme for the selection of the propeller in ship concept design. In Progress in Maritime Technology and Engineering; Guedes Soares, C., Santos, T.A., Eds.; Taylor \& Francis Group: London, UK, 2018; pp. 233-239.

8. Gaggero, S.; Tani, G.; Villa, D.; Viviani, M.; Ausonio, P.; Travi, P.; Bizzarri, G.; Serra, F. Efficient and multi-objective cavitating propeller optimization: An application to a high-speed craft. Appl. Ocean. Res. 2017, 64, 31-57. [CrossRef]

9. Tadros, M.; Ventura, M.; Guedes Soares, C. A nonlinear optimization tool to simulate a marine propulsion system for ship conceptual design. Ocean Eng. 2020, 210, 1-15. [CrossRef]

10. Harsha Vardhan, D.; Ramesh, A.; Chandra Mohan Reddy, B. A Review On Materials Used For Marine Propellers. Mater. Today Proc. 2019, 18, 4482-4490. [CrossRef]

11. Vettor, R.; Guedes Soares, C. Development of a ship weather routing system. Ocean Eng. 2016, 123, 1-14. [CrossRef]

12. van Lammeren, W.P.A.; van Manen, J.D.; Oosterveld, M.W.C. The Wageningen B-screw series. Trans. SNAME 1969, 77, $269-317$.

13. Oosterveld, M.; Van Oossanen, P. Further computer-analyzed data of the Wageningen B-screw series. Int. Shipbuild. Prog. 1975, 22, 251-262. [CrossRef]

14. HydroComp. NavCad: Reliable and Confident Performance Prediction. Available online: https://wwWhydrocompinc.com/ solutions/navcad/ (accessed on 30 January 2019).

15. Hillier, F.S.; Lieberman, G.J. Introduction to Operations Research; McGraw-Hill: New York, NY, USA, 1980.

16. Radojčić, D. Optimal Preliminary Propeller Design Using Nonlinear Constrained Mathematical Programming Technique; University of Southampton: Southampton, UK, 1985; Volume 21, pp. 1-22.

17. Suen, J.-b.; Kouh, J.-s. Genetic algorithms for optimal series propeller design. In Proceedings of the Third International Conference on Marine Technology; WIT press: Szczecin, Poland, 1999; pp. 1-10.

18. Benini, E. Multiobjective design optimization of B-screw series propellers using evolutionary algorithms. Mar. Technol. 2003, 40, 229-238.

19. Lee, C.-S.; Choi, Y.-D.; Ahn, B.-K.; Shin, M.-S.; Jang, H.-G. Performance optimization of marine propellers. Int. J. Nav. Archit. Ocean. Eng. 2010, 2, 211-216. [CrossRef]

20. Gaafary, M.M.; El-Kilani, H.S.; Moustafa, M.M. Optimum design of B-series marine propellers. Alex. Eng. J. 2011, 50, 13-18. [CrossRef]

21. Vesting, F.; Bensow, R. Propeller Optimisation Considering Sheet Cavitation and Hull Interaction. In Proceedings of the Second International Symposium on Marine Propulsors (SMP'11), Hamburg, Germany, 15-17 June 2011.

22. Xie, G. Optimal Preliminary Propeller Design Based on Multi-objective Optimization Approach. Procedia Eng. 2011, 16, 278-283. [CrossRef]

23. Mirjalili, S.; Lewis, A.; Mirjalili, S.A.M. Multi-objective Optimisation of Marine Propellers. Procedia Comput. Sci. 2015, 51, 2247-2256. [CrossRef]

24. Epps, B.P.; Stanway, M.J.; Kimball, R.W. OpenProp: An Open-source Design Tool for Propellers and Turbines. In Proceedings of the SNAME Propellers and Shafting Symposium, Williamsburg, VA, USA, 15-16 September 2009.

25. Khan, A.M. Flexible Composite Propeller Design Using Constrained Optimization Techniques. Ph.D. Thesis, Iowa State University, Ames, IA, USA, 1997.

26. Karim, M.; Ikehata, M. A genetic algorithm (GA)-based optimization technique for the design of marine propellers. In Proceedings of the Propeller/Shafting 2000 Symposium, SNAME, Virginia Beach, VA, USA, 20-21 September 2000.

27. Pluciński, M.M.; Young, Y.L.; Liu, Z. Optimization of a self-twisting composite marine propeller using genetic algorithms. In Proceedings of the 16th International Conference on Composite Materials, Kyoto, Japan, 8-13 July 2007.

28. Tadros, M.; Ventura, M.; Guedes Soares, C. Optimum design of a container ship's propeller from Wageningen B-series at the minimum BSFC. In Sustainable Development and Innovations in Marine Technologies; Georgiev, P., Guedes Soares, C., Eds.; Taylor \& Francis Group: London, UK, 2020; pp. 269-274.

29. DNV. Class Guideline: Calculation of Marine Propellers; DNV: Bærum, Norway, 2021.

30. Chen, J.-H.; Shih, Y.-S. Basic design of a series propeller with vibration consideration by genetic algorithm. J. Mar. Sci. Technol. 2007, 12, 119-129. [CrossRef]

31. Tadros, M.; Vettor, R.; Ventura, M.; Guedes Soares, C. Coupled Engine-Propeller Selection Procedure to Minimize Fuel Consumption at a Specified Speed. J. Mar. Sci. Eng. 2021, 9, 59. [CrossRef]

32. Michalsk, J.P. A method for selection of parameters of ship propulsion system fitted with compromise screw propeller. Pol. Marit. Res. 2007, 14, 3-6. [CrossRef]

33. Nelson, M.; Temple, D.W.; Hwang, J.T.; Young, Y.L.; Martins, J.R.R.A.; Collette, M. Simultaneous optimization of propeller-hull systems to minimize lifetime fuel consumption. Appl. Ocean Res. 2013, 43, 46-52. [CrossRef]

34. Tadros, M. Optimization Procedures to Minimize the Fuel Consumption of Marine Diesel Propulsion Systems. Ph.D. Thesis, University of Lisbon, Lisbon, Portugal, 2020.

35. Oosterveld, M.W.C. Wake Adapted Ducted Propellers. Ph.D. Thesis, Delft University of Technology, Delft, The Netherlands, 1970. 
36. Suh, J.C.; Lee, C.S. Polynomial Representation for MAU-Propeller Open Water Characteristics. Korean Inst. Mach. Mater. 1984, 11, 95-101.

37. Equasis. The World Merchant Fleet in 2019. Available online: https://www.equasis.org/EquasisWeb/restricted/About?fs= HomePage (accessed on 5 March 2020).

38. MAN Diesel \& Turbo. 32/44CR Project Guide-Marine. Available online: https://www.engines.man.eu (accessed on 31 August 2017).

39. The MathWorks Inc. Constrained Nonlinear Optimization Algorithms. Available online: https://www.mathworks.com/help/ optim/ug/constrained-nonlinear-optimization-algorithms.html (accessed on 3 February 2018).

40. Holtrop, J.; Mennen, G.G.J. An approximate power prediction method. Int. Shipbuild. Prog. 1982, 29, 166-170. [CrossRef]

41. Holtrop, J. A statistical re-analysis of resistance and propulsion data. Int. Shipbuild. Prog. 1984, 31, $272-276$.

42. ITTC. Uncertainty Analysis, Example for Resistance Test. In Proceedings of the 23th ITTC, Venice, Italy, 8-14 September 2002.

43. Tadros, M.; Ventura, M.; Guedes Soares, C. Optimization procedure to minimize fuel consumption of a four-stroke marine turbocharged diesel engine. Energy 2019, 168, 897-908. [CrossRef]

44. Tadros, M.; Ventura, M.; Guedes Soares, C. Simulation of the performance of marine genset based on double-Wiebe function. In Sustainable Development and Innovations in Marine Technologies; Georgiev, P., Guedes Soares, C., Eds.; Taylor \& Francis Group: London, UK, 2020; pp. 292-299.

45. Tadros, M.; Ventura, M.; Guedes Soares, C. Optimization of the performance of marine diesel engines to minimize the formation of SOx emissions. J. Mar. Sci. Appl. 2020, 19, 473-484. [CrossRef]

46. Tadros, M.; Ventura, M.; Guedes Soares, C. Surrogate models of the performance and exhaust emissions of marine diesel engines for ship conceptual design. In Maritime Transportation and Harvesting of Sea Resources; Guedes Soares, C., Teixeira, A.P., Eds.; Taylor \& Francis Group: London, UK, 2018; pp. 105-112.

47. Vettor, R.; Tadros, M.; Ventura, M.; Guedes Soares, C. Route planning of a fishing vessel in coastal waters with fuel consumption restraint. In Maritime Technology and Engineering 3; Guedes Soares, C., Santos, T.A., Eds.; Taylor \& Francis Group: London, UK, 2016; pp. 167-173.

48. Laurens, J.-M.; Leroux, J.-B.; Coache, S. Design and retrofit of the propulsion of trawlers to improve their efficiency. In Developments in Maritime Transportation and Exploitation of Sea Resources; Guedes Soares, C., López, P., Eds.; Taylor \& Francis Group: London, UK, 2013; pp. 1075-1084.

49. King-Sea Marine. Marine Propellers. Available online: http://www.kingseamarine.com/5_blade_mau_type_ship_propeller_13 06.html (accessed on 21 September 2021).

50. Burrill, L.C.; Emerson, A. Propeller cavitation: Further tests on 16in. propeller models in the King's College cavitation tunnel. Int. Shipbuild. Prog. 1963, 10, 119-131. [CrossRef]

51. Blount, D.L.; Fox, D.L. Design Considerations for Propellers in a Cavitating Environment. Mar. Technol. 1978, 15, 144-178. 